\title{
Phosphate triester dynamic covalent networks
}

Soumabrata Majumdar ${ }^{a}$, Huiyi Zhang ${ }^{a}$, Mohammad Soleimani ${ }^{b}$, Rolf A.T.M. van Benthem ${ }^{\text {b,c }}$, Johan P.A. Heuts ${ }^{a *}$, and Rint P. Sijbesma ${ }^{a *}$.

aDepartment of Chemical Engineering \& Chemistry and Institute for Complex Molecular Systems, Eindhoven University of Technology, PO Box 513, 5600 MB Eindhoven, The Netherlands.

${ }^{b}$ Department of Chemical Engineering \& Chemistry, Laboratory of Physical Chemistry and Center for Multiscale Electron Microscopy, Eindhoven University of Technology, PO Box 513, 5600 MB Eindhoven, The Netherlands.

'DSM Materials Science Center, Urmonderbaan 22, 6167 RD Geleen, The Netherlands.

Corresponding authors:

j.p.a.heuts@tue.nl, r.p.sijbesma@tue.nl

\section{Materials}

All reagents and solvents were used as obtained without further purification unless mentioned otherwise. Polytetrahydrofuran $\left(\mathrm{M}_{\mathrm{n}} \approx 650 \mathrm{~g} / \mathrm{mol}\right)$ (pTHF), Triphenyl phosphate ( $\left.\geq 99 \%\right)$, Diphenyl phosphate (99\%), Sodium hydride (dry, 90\%) and 2-Decanol (98\%) were purchased from Sigma Aldrich. Toluene and tetrahydrofuran were purchased from Biosolve. Toluene was maintained dry with $3 \AA$ molecular sieves.

\section{Synthesis}

Synthesis of trialkyl phosphate crosslinked pTHF network (pTHF-PX)

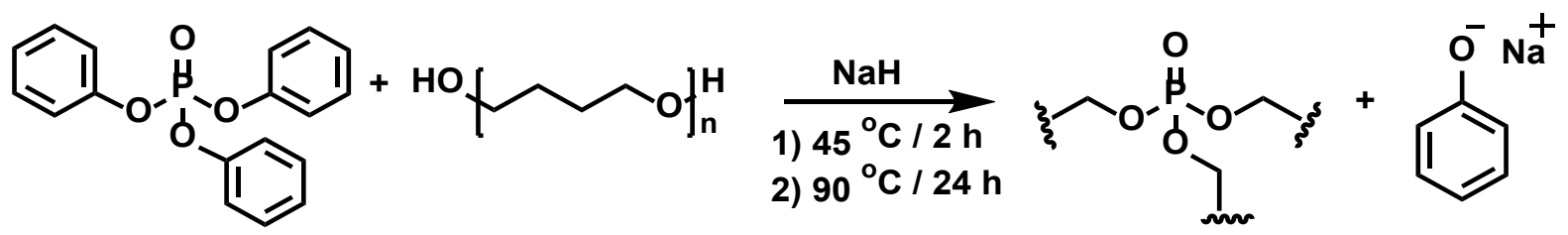

$20 \mathrm{~g}$ (30.7 mmol) polytetrahydrofuran (pTHF) $\left(\mathrm{M}_{\mathrm{n}} \sim 650 \mathrm{~g} / \mathrm{mol}\right)$ was dried by coevaporation with toluene using a Dean-Stark setup for $18 \mathrm{~h}$. The remaining solvent was evaporated, and the polymer was re-dissolved in $\sim 75 \mathrm{~mL}$ toluene. The reaction vessel was set at $45^{\circ} \mathrm{C}$ under argon flow. $1.23 \mathrm{~g}$ (51.1 $\mathrm{mmol}$ ) sodium hydride was added to the reaction vessel in parts while controlling the effervescence due to hydrogen gas formation. The reaction mixture was further stirred for $2 \mathrm{~h}$ then $5.57 \mathrm{~g}$ (17.1 mmol) triphenyl phosphate was added to the reaction mixture. The resultant reaction mixture was then stirred at $45^{\circ} \mathrm{C}$ for $2 \mathrm{~h}$. The oil bath temperature was then raised to $90^{\circ} \mathrm{C}$ and the reaction was continued for $24 \mathrm{~h}$ to yield a white solid. The material was then extracted with acetone and washed in acetone-water mixture (1:1) for 8 cycles allowing a minimum swelling time of $5 \mathrm{~h}$ at $4{ }^{\circ} \mathrm{C}$ for every cycle to wash off the sodium phenolate from the material. The material was then freeze dried to obtain the final product. The efficient removal of sodium phenolate was checked by heating the network at $180^{\circ} \mathrm{C}$ in 2-Decanol and performing ${ }^{1} \mathrm{H}$ NMR on the resultant solution.

Synthesis of trialkyl phosphate crosslinked pTHF network with excess phosphate diester monoanion links (pTHF-PX-diester)

$10 \mathrm{~g}(15.38 \mathrm{mmol})$ polytetrahydrofuran (pTHF) $\left(\mathrm{M}_{\mathrm{n}} \sim 650 \mathrm{~g} / \mathrm{mol}\right)$ was dried by coevaporation with toluene using a Dean-Stark setup for $18 \mathrm{~h}$. The remaining solvent was evaporated, and the polymer 
was re-dissolved in $40 \mathrm{~mL}$ dry toluene. The reaction vessel was set at $45^{\circ} \mathrm{C}$ under argon flow. $0.81 \mathrm{~g}$ (33.8 mmol) sodium hydride was added to the reaction vessel in parts while controlling the effervescence due to hydrogen gas formation. The reaction mixture was further stirred for $2 \mathrm{~h}$ then a

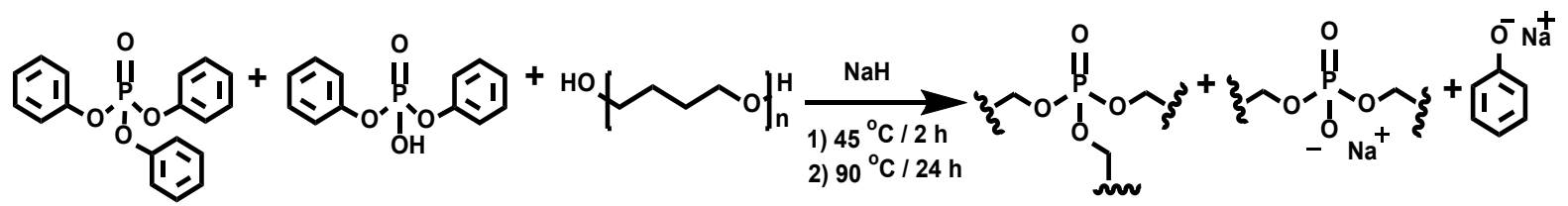

mixture of $2.67 \mathrm{~g}(8.2 \mathrm{mmol})$ triphenyl phosphate and $0.76 \mathrm{~g}(3.1 \mathrm{mmol})$ diphenyl phosphate was gradually added to the reaction mixture. The resultant reaction mixture was then stirred at $45^{\circ} \mathrm{C}$ for $2 \mathrm{~h}$. The oil bath temperature was then raised to $90^{\circ} \mathrm{C}$ and the reaction was continued for $24 \mathrm{~h}$ to yield a white solid. The material was then extracted with acetone and washed in acetone-water mixture (1:1) for 8 cycles allowing a minimum swelling time of $5 \mathrm{~h}$ at $4{ }^{\circ} \mathrm{C}$ for every cycle to wash off the sodium phenolate from the material. The material was then freeze dried to obtain the final product.

\section{Transesterification on pTHF-PX}

$150 \mathrm{mg}$ pTHF-PX was swollen in $1 \mathrm{~mL}$ of 2-Decanol in an argon purged sealed vessel and heated at 180 ${ }^{\circ} \mathrm{C}$ for $14 \mathrm{~h} .{ }^{31} \mathrm{P} N M R$ and ${ }^{1} \mathrm{H}$ NMR was performed on the resulting solution.

\section{Characterization}

\section{Yield calculation}

The yield was calculated in terms weight percent of final material obtained with respect to the theoretical maximum weight assuming complete removal of sodium phenoxide.

\section{Gel fraction and swelling ratio analysis}

For the gel fraction analysis, dry sample was weighed $\left(m_{\text {initial }}\right)$ and then allowed to swell in tetrahydrofuran (THF) for $48 \mathrm{~h}$. The swollen gel was then removed washed with excess THF and then dried in vacuum oven for $8 \mathrm{~h}$ at $100^{\circ} \mathrm{C}$. The dried material was then weighed $\left(m_{\text {dry }}\right)$, and gel fraction was calculated using equation S1a.

$$
\% \text { gel fraction }=\frac{m_{\text {dry }}}{m_{\text {initial }}} \times 100(\%)
$$

For swelling ratio analysis, a dry compression molded sample was weighed ( $m_{\text {initial }}$ ) and the exact dimensions (radius initial, thickness $_{\text {initial) }}$ were measured using a vernier calliper. The sample was then allowed to swell in THF for $48 \mathrm{~h}$. The swollen sample was then removed, gently tap dried on a filter paper and weighed $\left(\mathrm{m}_{\text {swollen }}\right)$. The dimensions ( radius $_{\text {swollen, }}$ thickness $\left.s_{\text {swollen }}\right)$ were re-measured post swelling. Swelling ratio based on both weight $(w)$ and volume $(v)$ was measured using equation S1b and $\mathrm{S} 1 \mathrm{c}$ respectively.

$$
\begin{gathered}
\text { Swelling ratio }(w)=\frac{m_{\text {swollen }}}{m_{\text {initial }}} \\
\text { Swelling ratio }(v)=\frac{\text { radius }_{\text {swollen }}^{2} \times \text { thickness }_{\text {swollen }}}{\text { radius }_{\text {initial }}^{2} \text { thickness } s_{\text {initial }}}
\end{gathered}
$$


Phosphorous nuclear magnetic resonance spectroscopy $\left({ }^{31} P-N M R\right)$ of $p$ THF-PX.

${ }^{31} \mathrm{P}-\mathrm{NMR}$ spectroscopy measurements were performed on a $400 \mathrm{MHz}$ Bruker Avance III spectrometer at $25{ }^{\circ} \mathrm{C}$. The network was swollen in $\mathrm{CDCl}_{3}$ and the spectra was measured with recycle delay of $5 \mathrm{~s}$ and a spectral width of $64102 \mathrm{~Hz}$.

Attenuated total reflectance infrared (ATR-IR) spectroscopy

ATR-IR spectroscopy was performed with Perkin Elmer FT-IR Spectrum Two apparatus.

Dynamic mechanical thermal analysis (DMTA)

DMTA was performed on rectangular shaped compression molded samples of dimensions $25 \mathrm{~mm} \mathrm{X}$ $14.5 \mathrm{~mm} \times 1 \mathrm{~mm}$ using film tension setup in a DMA Q850 (TA instruments). A temperature ramp was performed from $-60{ }^{\circ} \mathrm{C}$ to $200{ }^{\circ} \mathrm{C}$ at a heating rate of $3{ }^{\circ} \mathrm{C} / \mathrm{min}$ under oscillatory strain of $0.1 \%$ and frequency of $1 \mathrm{~Hz}$. A preload force of $0.01 \mathrm{~N}$ and force track of $110 \%$ was used. The storage and the loss modulus were recorded as a function of temperature and $T_{\mathrm{g}}$ was determined from the maxima in $\tan \delta$

\section{Thermogravimetric analysis (TGA)}

Thermal stability of the material was analysed using a TGA Q500 (TA instruments) under $\mathrm{N}_{2}$ flow. The temperature ramp was performed from $30{ }^{\circ} \mathrm{C}$ to $600{ }^{\circ} \mathrm{C}$ at $10^{\circ} \mathrm{C} / \mathrm{min}$. Temperature calibration was performed using the Curie points of high purity aluminum, nickel and perkalloy standards.

Scanning electron microscopy and Energy dispersive X-ray spectroscopy (SEM-EDS)

SEM-EDS elemental mappings were conducted in SEM Quanta 3D FEG (Thermo Fisher Scientific, USA) at an acceleration voltage of $10 \mathrm{kV}$. Phenom ProX SEM (Thermo Fisher Scientific, USA) at an accelerating voltage of $15 \mathrm{kV}$ was used for EDS spot measurements.

Atomic absorption spectroscopy (AAS)

The sodium ( $\mathrm{Na}$ ) content in the material was determined using an atomic absorption spectrometer (Shimadzu AA7000, Japan) with a hollow cathode lamp at a wavelength of $589 \mathrm{~nm}$ and using an airacetylene flame.

Due to the insolubility of samples in water which is a universal solvent for AAS we used dry ashing method to prepare samples for quantitatively measurement of Na content. $500 \mathrm{mg}$ of each sample was calcined at $500^{\circ} \mathrm{C}$ in air for 2 hours. Then, the remaining ashes were collected carefully and dispersed in $10 \mathrm{~mL}$ distilled water. Subsequently, a sonication bath was used to disperse the agglomerated ashes and ensure the dissolution of the Na compounds. Then, the residual was filtered out to obtain a transparent solution. Finally, prior to the measurements, a series of dilutions was conducted to reach the linear range of the atomic absorption spectrometer.

\section{Rheology experiment}

All rheology studies were performed using AR-G2 rheometer with an ETC oven setup (TA Instruments) and parallel-plate geometry. The samples were compression molded at $160{ }^{\circ} \mathrm{C}$ for 40 mins into disks with diameter $8 \mathrm{~mm}$ and thickness $0.8 \mathrm{~mm}$. All experiments were performed with an axial force range of $5 \pm 1 \mathrm{~N}$. The samples have been subjected to thermal treatment with oscillatory shear at $220^{\circ} \mathrm{C}$ for 20 mins prior to the experiments to ensure similar thermal history and extent of curing for all samples. 


\section{Stress relaxation experiment}

Stress relaxation experiments were performed with temperature variation from $140{ }^{\circ} \mathrm{C}$ to $220^{\circ} \mathrm{C}$. The relaxation modulus $(\mathrm{G}(\mathrm{t}))$ was followed over different time periods for a constant applied strain of $1 \%$. All the stress relaxation plots have been normalised at $1 \mathrm{~s}$ to be able to compare the relaxation rates.

All the normalized stress relaxation plots were fitted with a stretched exponential function normalized to $1 \mathrm{~s}$ (equation S2) and the characteristic relaxation times $(\tau)$, obtained, have been plotted in an Arrhenius plot. The activation energy for flow can be derived from the slope of the Arrhenius plot according to equation (equation S3).

$$
\begin{aligned}
& \frac{G(t)}{G_{(1 s)}}=\frac{e^{-\left(\frac{t}{\tau}\right) \beta}}{e^{-\left(\frac{1}{\tau}\right) \beta}} \\
& \ln (\tau)=\ln \left(\tau_{0}\right)+\frac{E_{a}}{R T}
\end{aligned}
$$

\section{Creep experiment}

Creep experiments were performed with $1000 \mathrm{~Pa}$ applied stress at temperatures from $160{ }^{\circ} \mathrm{C}$ to 220 ${ }^{\circ} \mathrm{C}$. \%Strain was followed over time. The constant creep rate of the secondary creep phase was plotted in an Arrhenius plot and the activation energy of flow was calculated from the Arrhenius plot using equation S4. Creep recovery experiments have also been performed under $1.5 \times 10^{5} \mathrm{~Pa}$ at $180{ }^{\circ} \mathrm{C}$ to illustrate deformations under high stresses.

$$
-\ln \left(\frac{d \gamma}{d t}\right)=\ln A+\frac{E_{a}}{R T}
$$

\section{Frequency sweep experiment}

Frequency sweep from $10^{-3} \mathrm{rad} / \mathrm{s}$ to $10^{2} \mathrm{rad} / \mathrm{s}$ was performed on $\mathrm{PTHF}-\mathrm{PX}$ at different temperatures. The oscillation amplitude was set to $1000 \mathrm{~Pa}$. The storage modulus, loss modulus and $\tan \delta$ were followed as a function of frequency.

\section{Oscillatory time sweep experiment}

Oscillatory time sweep experiments were performed before and after stress relaxation experiments at the same temperature to ensure that the relaxation is brought about by network rearrangement and not network degradation. The oscillatory experiments were performed with $1 \%$ oscillatory strain and a frequency of $1 \mathrm{~Hz}$. The storage modulus was followed with time.

Oscillatory time sweep experiments were performed on compression molded pTHF-PX discs soaked in pTHF at $20^{\circ} \mathrm{C}$ for $48 \mathrm{~h}$. Upon soaking in pTHF, the mass of the sample increased from $57.7 \mathrm{mg}$ to $115.6 \mathrm{mg}$ ( $100 \%$ increase of mass). Three consecutive time oscillation experiments were performed. Firstly, the sample was subjected to oscillatory shearing at $100{ }^{\circ} \mathrm{C}$ with an amplitude of $1 \%$ strain and $1 \mathrm{~Hz}$ frequency for $300 \mathrm{~s}$. Then the same sample was put into oscillation at $200{ }^{\circ} \mathrm{C}$ for $10^{4} \mathrm{~s}$ with $1 \%$ strain amplitude and a frequency of $1 \mathrm{~Hz}$. Lastly, the sample was cooled to a $100^{\circ} \mathrm{C}$ and another time oscillation experiment was performed with $1 \%$ strain and $1 \mathrm{~Hz}$ frequency. In each case the storage modulus was followed as a function of time.

Extent of network degradation by hydrolysis was also studied with oscillatory time sweep experiments on a compression molded disc of pTHF-PX before and after swelling the sample in 1:1 (v/v) mixture of 
acetone-water for $25 \mathrm{~d}$. The experiments were performed at $220^{\circ} \mathrm{C}$ with $1 \%$ strain amplitude and 1 $\mathrm{Hz}$ frequency. In both cases the sample was freeze dried before performing the experiment.

\section{Tensile testing}

The tensile tests were performed in an Easy test, EZ20 (Lloyd instrument) with a $500 \mathrm{~N}$ load cell. The strain at break of the material in subsequent processing cycles was determined. The material was completely shredded before each cycle of compression molding. The tensile bars had an effective length of $10 \mathrm{~mm}$, width of $2 \mathrm{~mm}$ and an average thickness of $0.8 \mathrm{~mm}$. The elongation rate used, was $30 \mathrm{~mm} / \mathrm{min}$.

\section{Results}

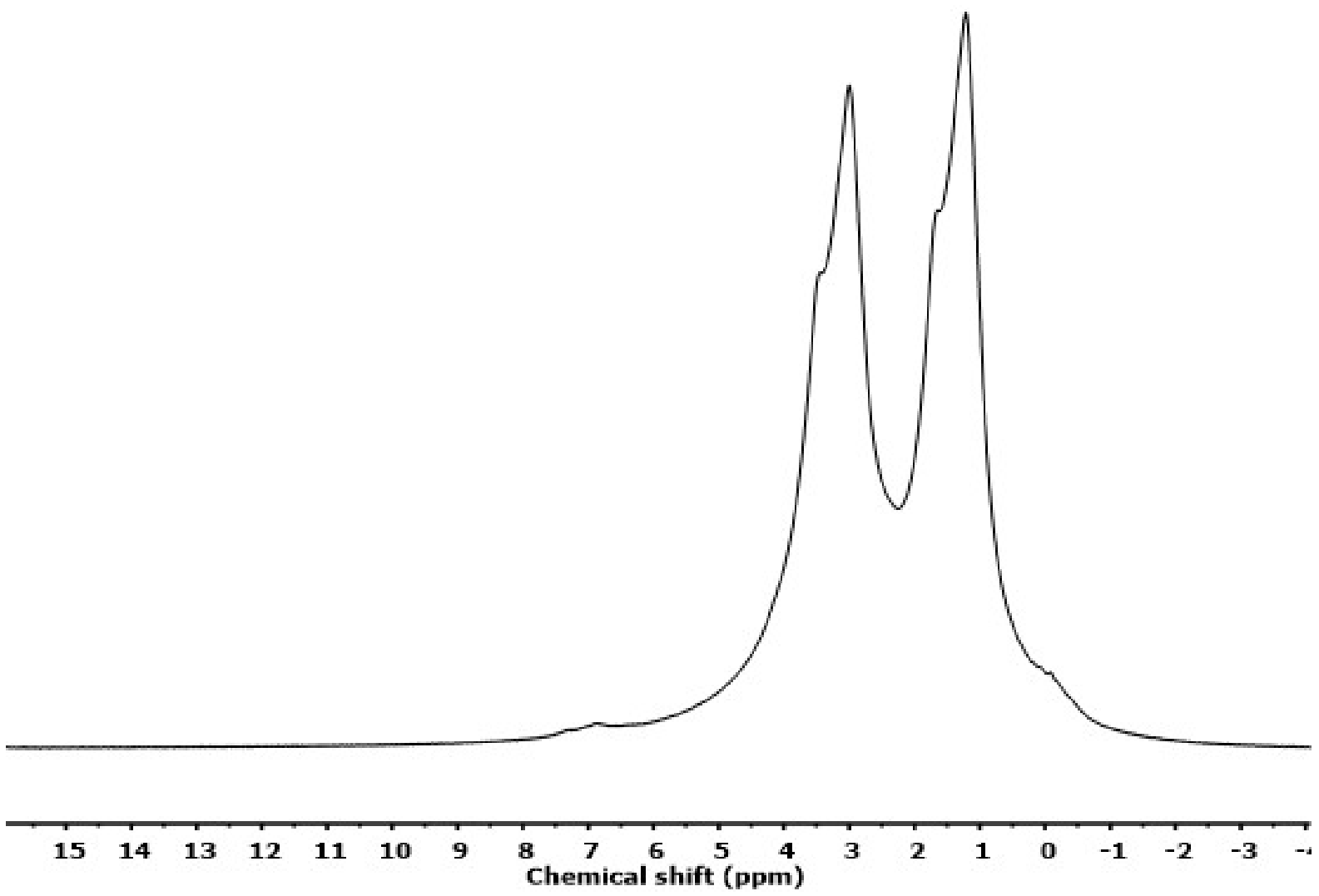

Figure S1. ${ }^{1} \mathrm{H}$ NMR of pTHF-PX swollen in $\mathrm{CDCl}_{3}$ 


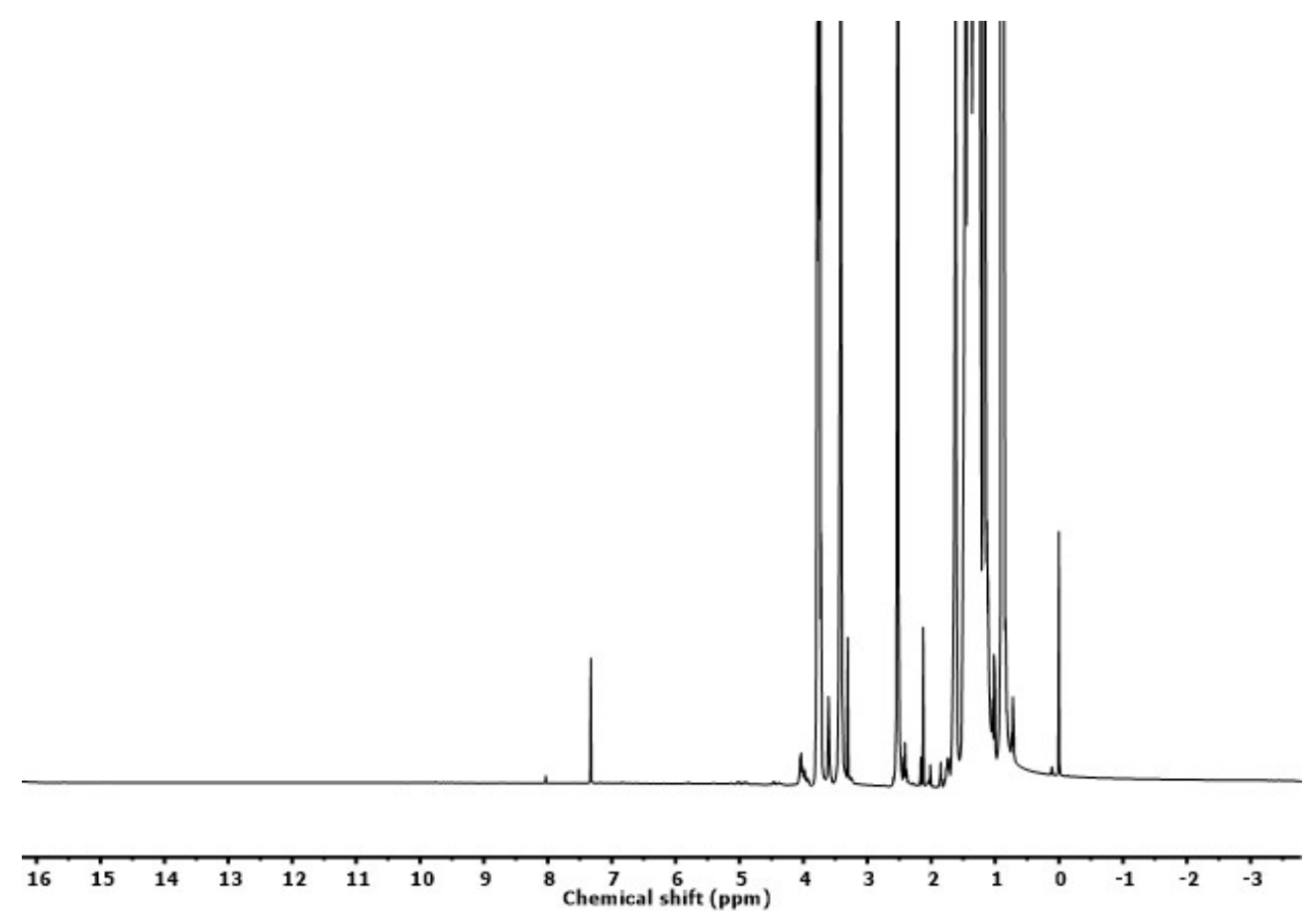

Figure S2. ${ }^{1} \mathrm{H}$ NMR of pTHF-PX dissolved in 2-Decanol (in $\mathrm{CDCl}_{3}$ ) shows efficient removal of sodium phenoxide

ATR-IR spectrum of $p T H F-P X$

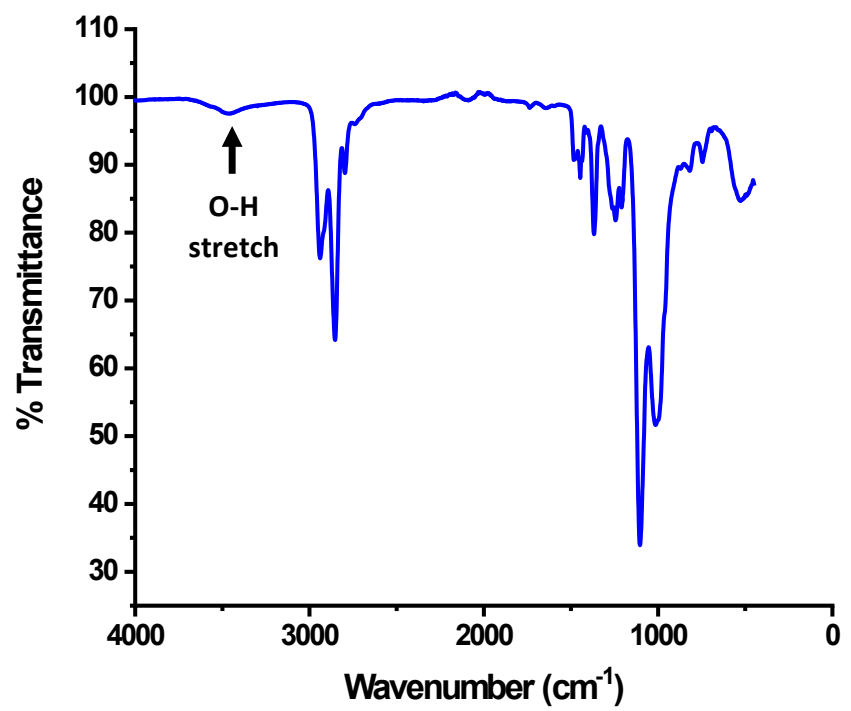

Figure S3. ATR-IR spectrum on PTHF-PX confirms the presence of excess $\mathrm{OH}$ in the network responsible for the network rearrangement via transesterification. 


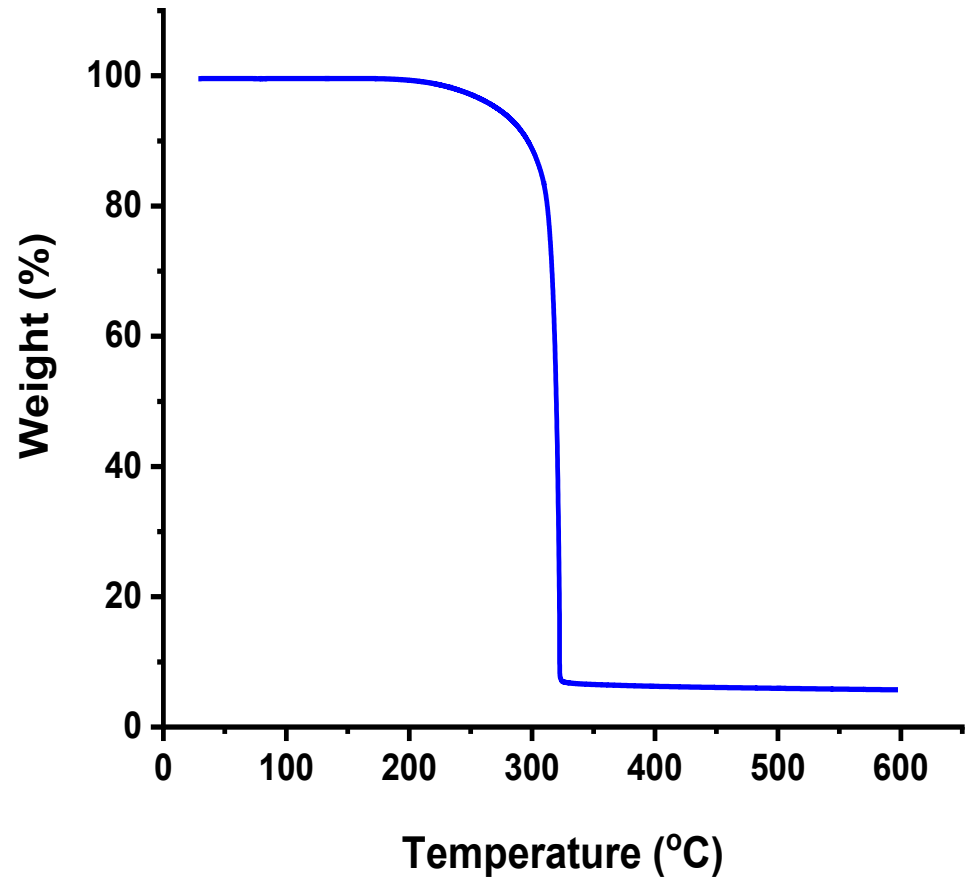

Figure S4. TGA on pTHF-PX TGA shows that material is thermally stable up to $200{ }^{\circ} \mathrm{C}$
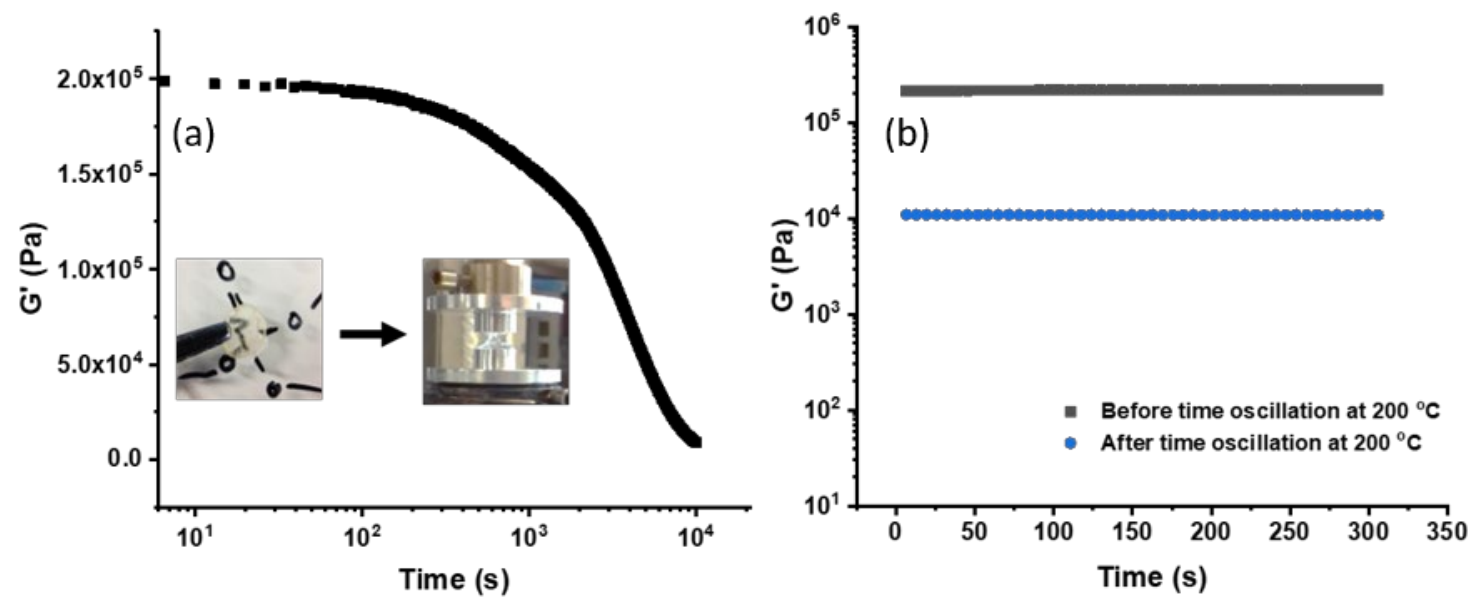

Figure S5. (a) Oscillatory shear on pTHF-PX swollen in excess PTHF at $200^{\circ} \mathrm{C}$. The drop in storage modulus $\left(\mathrm{G}^{\prime}\right)$ signifies the incorporation of pTHF into the network through transesterification resulting in lowering of crosslink density.(b) Oscillatory shear on the same sample at $100^{\circ} \mathrm{C}$ before and after the experiment at $200^{\circ} \mathrm{C}$ 

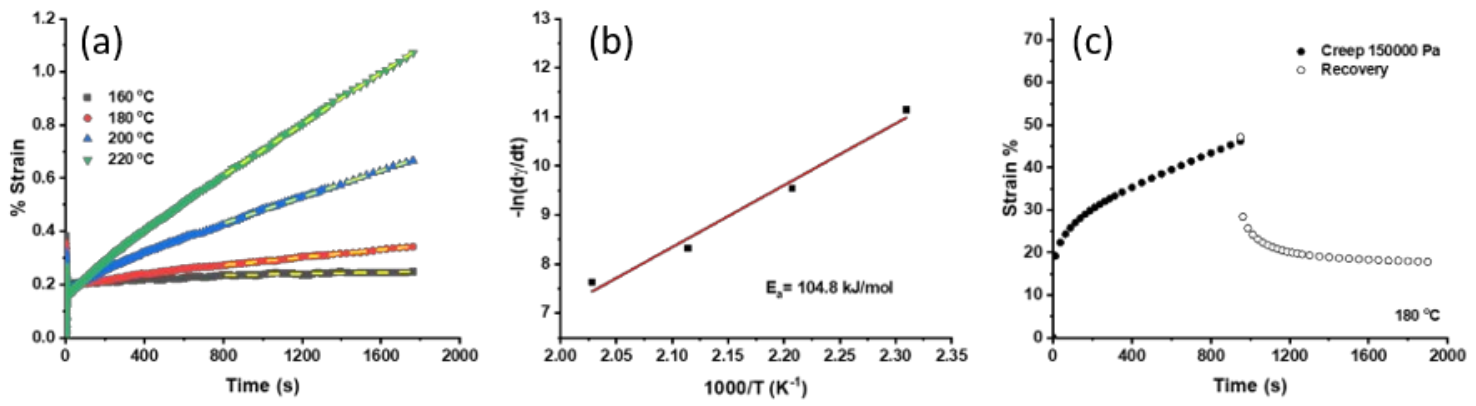

Figure S6. a) Linear fit of the secondary creep phase of pTHF-PX at different temperatures. b) Arrhenius plot based on the strain rates at different temperatures. The derived activation energy for flow is $104.8 \mathrm{~kJ} / \mathrm{mol}$. c) Creep recovery experiment under $1.5 \times 10^{5} \mathrm{~Pa}$ at $180^{\circ} \mathrm{C}$ showing significant permanent deformation in the material.

Table S1. Parameters obtained from linear fits on the secondary creep phase at different temperatures.

$\begin{array}{lll}\text { Temperature } & \mathrm{d} \boldsymbol{d} / \mathrm{dt}\left(\mathbf{1 0 ^ { - 5 } \mathrm { s } ^ { - 1 } )}\right. & -\ln (\mathrm{d} \gamma / \mathrm{dt}) \\ 160^{\circ} \mathrm{C} & 1.28148 & 11.26491 \\ 180^{\circ} \mathrm{C} & 7.26246 & 9.53021 \\ 200^{\circ} \mathrm{C} & 24.9307 & 8.29683 \\ 220^{\circ} \mathrm{C} & 48.4017 & 7.63339\end{array}$

\section{Stress relaxation experiments}
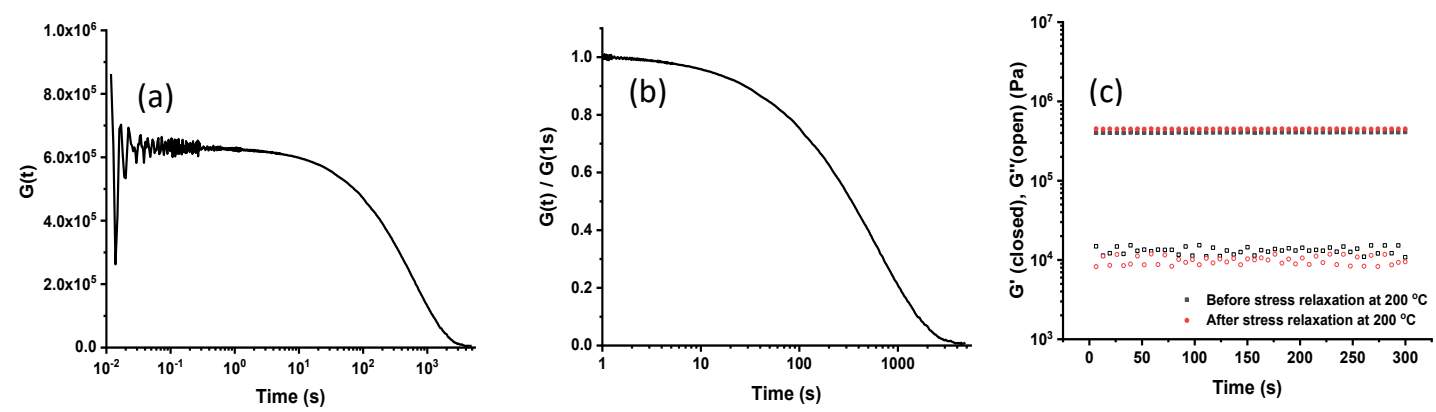

Figure S7. a) Stress relaxation data as acquired for pTHF-PX at $200{ }^{\circ} \mathrm{C}$ under $1 \%$ strain; the instrument roughly requires $1 \mathrm{~s}$ to equilibrate the material under the applied strain. b) the corresponding normalized stress relaxation plot. c) Time oscillation experiment before and after stress relaxation experiment showing that the relaxation is due to topological rearrangement in the network and not degradation. 

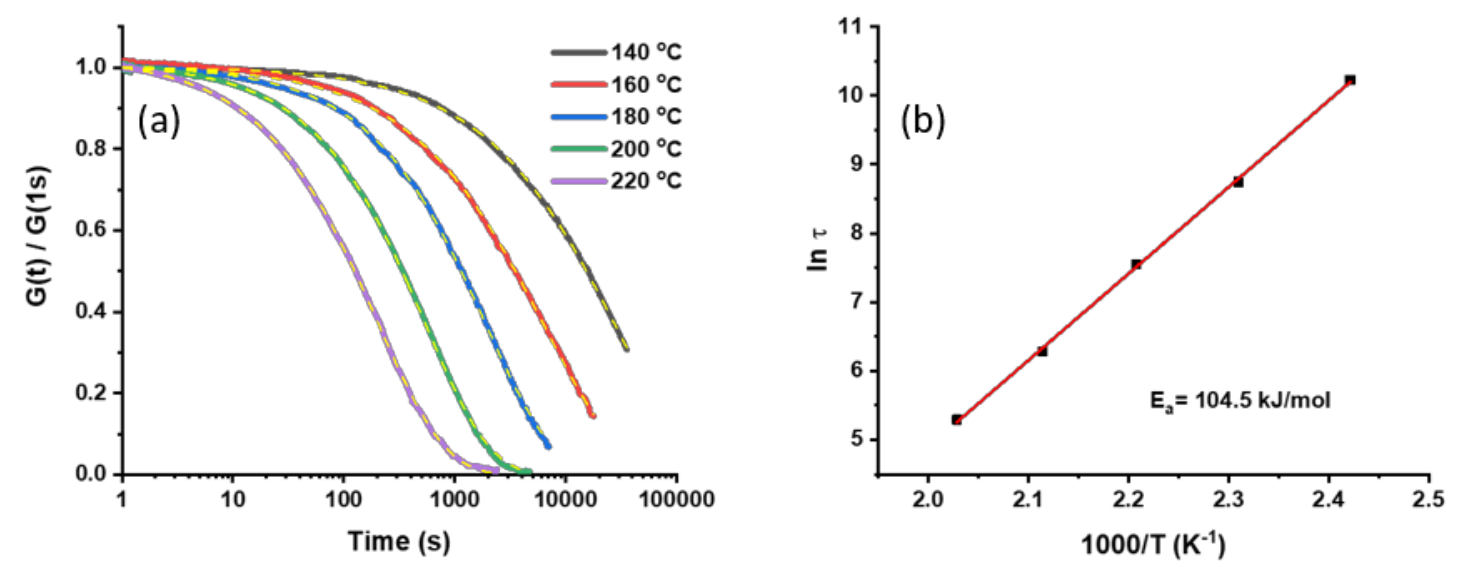

Figure S8. a) Normalized stress relaxation plots for pTHF-PX under $1 \%$ strain, fitted with equation S2. b) Arrhenius plot using the characteristic relaxation times obtained by fitting the stress relaxation plots with equation S2. The derived activation energy for flow is $104.5 \mathrm{~kJ} / \mathrm{mol}$.

Table S2. Parameters obtained from the stretched exponential fits on stress relaxation plots.

$\begin{array}{lll}\text { Temperature } & \beta \text { value } & \tau(\mathbf{s}) \\ 140^{\circ} \mathrm{C} & 0.617 & 27679 \\ 160^{\circ} \mathrm{C} & 0.621 & 6275 \\ 180^{\circ} \mathrm{C} & 0.705 & 1896 \\ 200^{\circ} \mathrm{C} & 0.739 & 538 \\ 220^{\circ} \mathrm{C} & 0.706 & 199\end{array}$
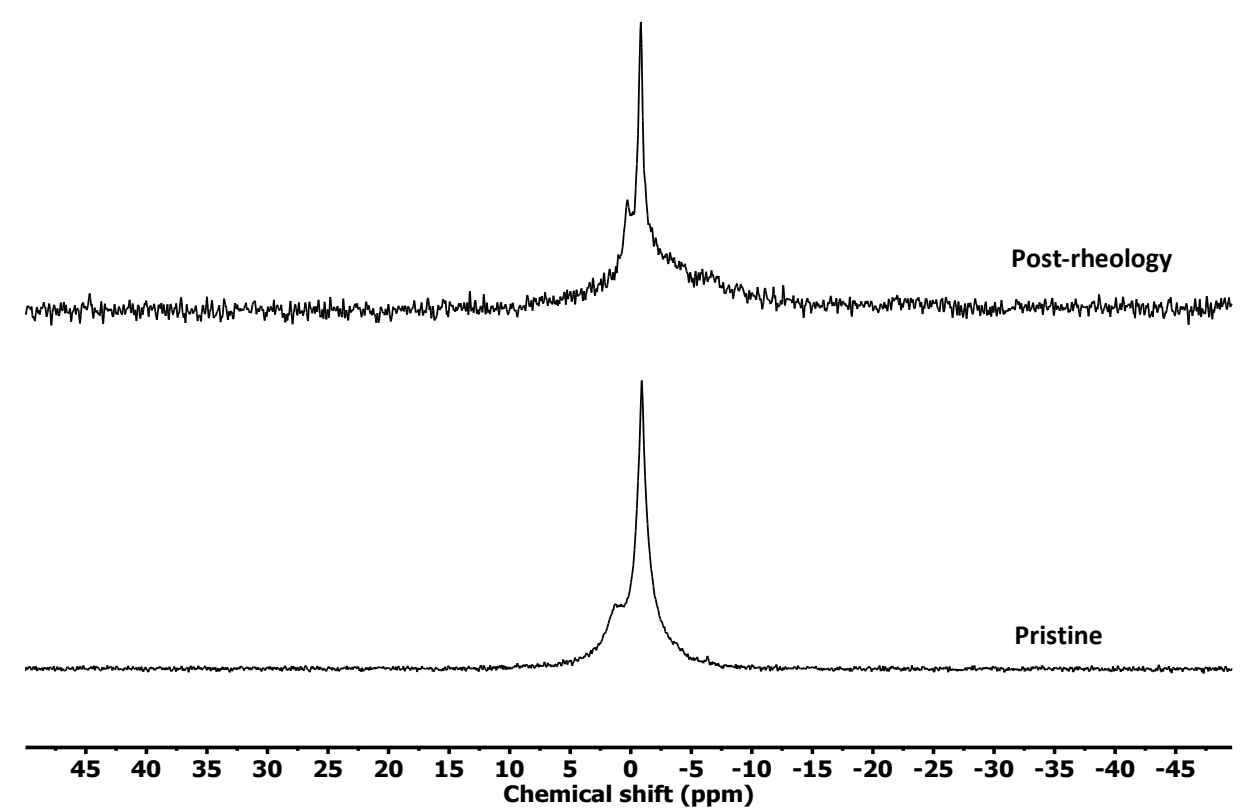

Figure S9. ${ }^{31} \mathrm{P}$ NMR spectra of pTHF-PX swollen in $\mathrm{CDCl}_{3}$ before (below) and after (above) frequency sweep at $200^{\circ} \mathrm{C}$ showing no significant chemical alteration at the crosslinks. 
Comparison of pTHF-PX moduli from tensile testing, DMTA, creep test and stress relaxation

Table S3. Moduli from tensile testing, DMTA, creep test and stress relaxation

\begin{tabular}{|c|c|c|c|c|c|}
\hline $\begin{array}{c}\text { Temperature } \\
\left({ }^{\circ} \mathrm{C}\right)\end{array}$ & $\begin{array}{c}\text { Young's } \\
\text { Modulus } \\
(\text { Tensile test }) \\
\left(10^{5} \mathrm{~Pa}\right)\end{array}$ & $\begin{array}{c}\text { Storage modulus } \\
\left(\mathrm{E}^{\prime}\right)(\mathrm{DMTA}) \\
\left(10^{5} \mathrm{~Pa}\right)\end{array}$ & $\begin{array}{c}3 \times \mathrm{G}^{\prime} \text { in } \\
\text { oscillatory } \\
\text { shear }\left(10^{5} \mathrm{~Pa}\right)^{\mathrm{a}}\end{array}$ & $\begin{array}{c}3 \times \mathrm{G}^{\prime} \text { from } \\
\text { creep } \\
\left(10^{5} \mathrm{~Pa}\right)^{\mathrm{a}}\end{array}$ & $\begin{array}{c}3 \times \mathrm{G}(1 \mathrm{~s}) \text { from } \\
\text { stress relaxation } \\
\left(10^{5} \mathrm{~Pa}\right)^{\mathrm{a}}\end{array}$ \\
\hline 25 & 6.3 & 8.7 & & & $15.0^{\mathrm{c}}$ \\
\hline 160 & & $9.6^{\mathrm{b}}$ & & & $16.9^{\mathrm{c}}$ \\
\hline 220 & & & $9.4^{\mathrm{b}} / 15.7^{\mathrm{c}} / 26.5^{\mathrm{d}}$ & & \\
\hline
\end{tabular}

a shear moduli are multiplied by 3 for comparison with $\mathrm{E}^{\prime}{ }^{\mathrm{b}}$ without conditioning; after conditioning at $220^{\circ} \mathrm{C}$ for ${ }^{\mathrm{c}} 20 \mathrm{~min},{ }^{\mathrm{d}} 2 \mathrm{~h}$

The Young's modulus from tensile testing and storage modulus ( $\left.E^{\prime}\right)$ from DMTA at $25^{\circ} \mathrm{C}$ have values that are somewhat different, probably because of difference in topology in different batches of material.

The storage modulus measured in oscillatory shear at $220^{\circ} \mathrm{C}$ showed an increase in $\mathrm{G}^{\prime}$ from $3.15 \times 10^{5}$ $\mathrm{Pa}$ to $8.83 \times 10^{5} \mathrm{~Pa}$ over $2 \mathrm{~h}$ (Figure S10). Samples for creep and stress relaxation experiments (also performed in shear), were pre-conditioned at $220^{\circ} \mathrm{C}$ for 20 mins to have reduced effect of modulus increase during the experiment (Figure S7c).

The storage modulus in creep was calculated from the short time strain (0.2\%) at an applied stress of $10^{3} \mathrm{~Pa}$ ), while the relaxation modulus in a stress relaxation experiment was determined at $1 \%$ strain. The values of the storage modulus from the creep experiment $\left(5.010^{5} \mathrm{~Pa}\right)$ and the initial relaxation modulus in the stress relaxation experiment $\left(5.6 \times 10^{5} \mathrm{~Pa}\right)$ comply with the storage modulus of the material determined after 20 mins of thermal treatment at $220^{\circ} \mathrm{C}$ under shear.

\section{Estimate of crosslink density}

The crosslink density before and after conditioning was estimated using equation $\mathrm{S} 6$, where $\mathrm{G}^{\prime}$ is the storage modulus, $R$ is the universal gas constant, $T$ is the absolute temperature, $v_{e}$ is the crosslink density, $f$ is the functionality of the crosslink $(=3)$ and $v_{2}$ is the volume fraction which in this case, is 1 because experiment is performed on bulk material. ${ }^{1,2}$

$$
G=\left(1-\frac{2}{f}\right) v_{e} R T v_{2}^{\frac{2}{3}}
$$

These values can be compared to the concentration of phosphate groups in the material $\left(10^{3}\right.$ $\mathrm{mole} / \mathrm{m}^{3}$

Table S4: Calculated crosslink densities before and after thermal treatment at $220^{\circ} \mathrm{C}$.

\begin{tabular}{|l|l|l|}
\hline & $\mathrm{G}^{\prime}\left(10^{5} \mathrm{~Pa}\right)$ & Crosslink density $\left(10^{3} \mathrm{moles} / \mathrm{m}^{3}\right)$ \\
\hline Before thermal treatment & 3.15 & 0.23 \\
\hline After thermal treatment & 8.83 & 0.65 \\
\hline
\end{tabular}



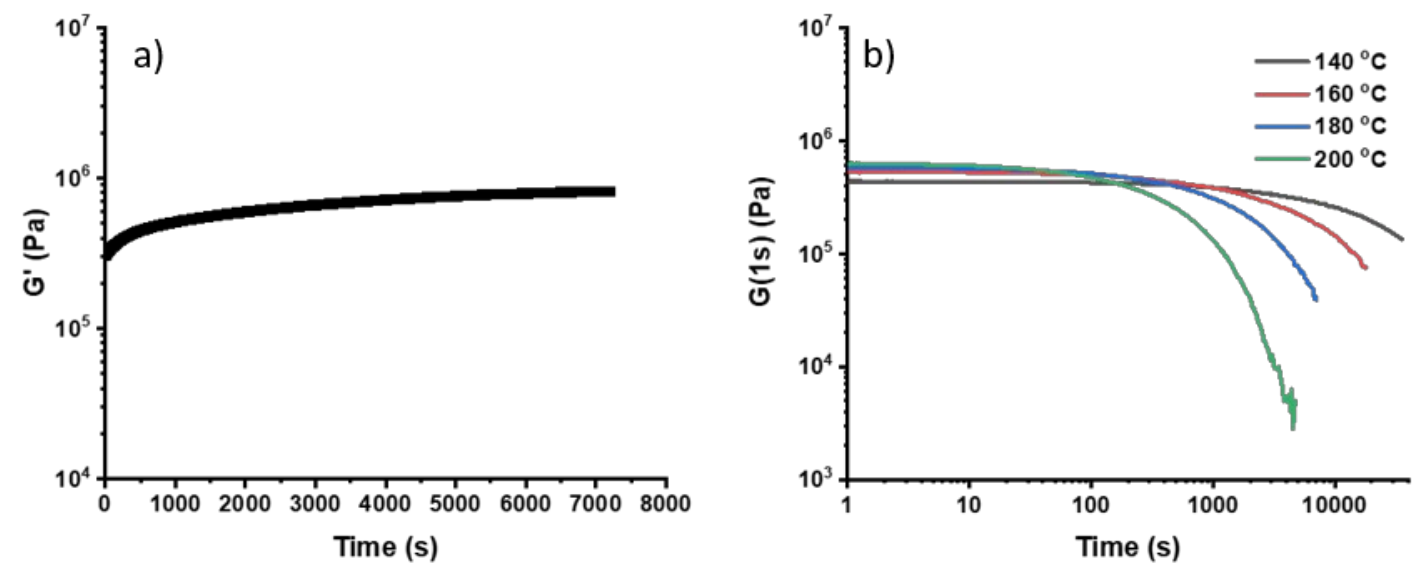

Figure S10. a) Storage modulus as a function of time in pTHF-PX samples at $220^{\circ} \mathrm{C}$ at $1 \mathrm{~Hz}$ showing increase in $\left.\mathrm{G}^{\prime}, \mathrm{b}\right)$ Relaxation modulus from stress relaxation experiment at different temperatures

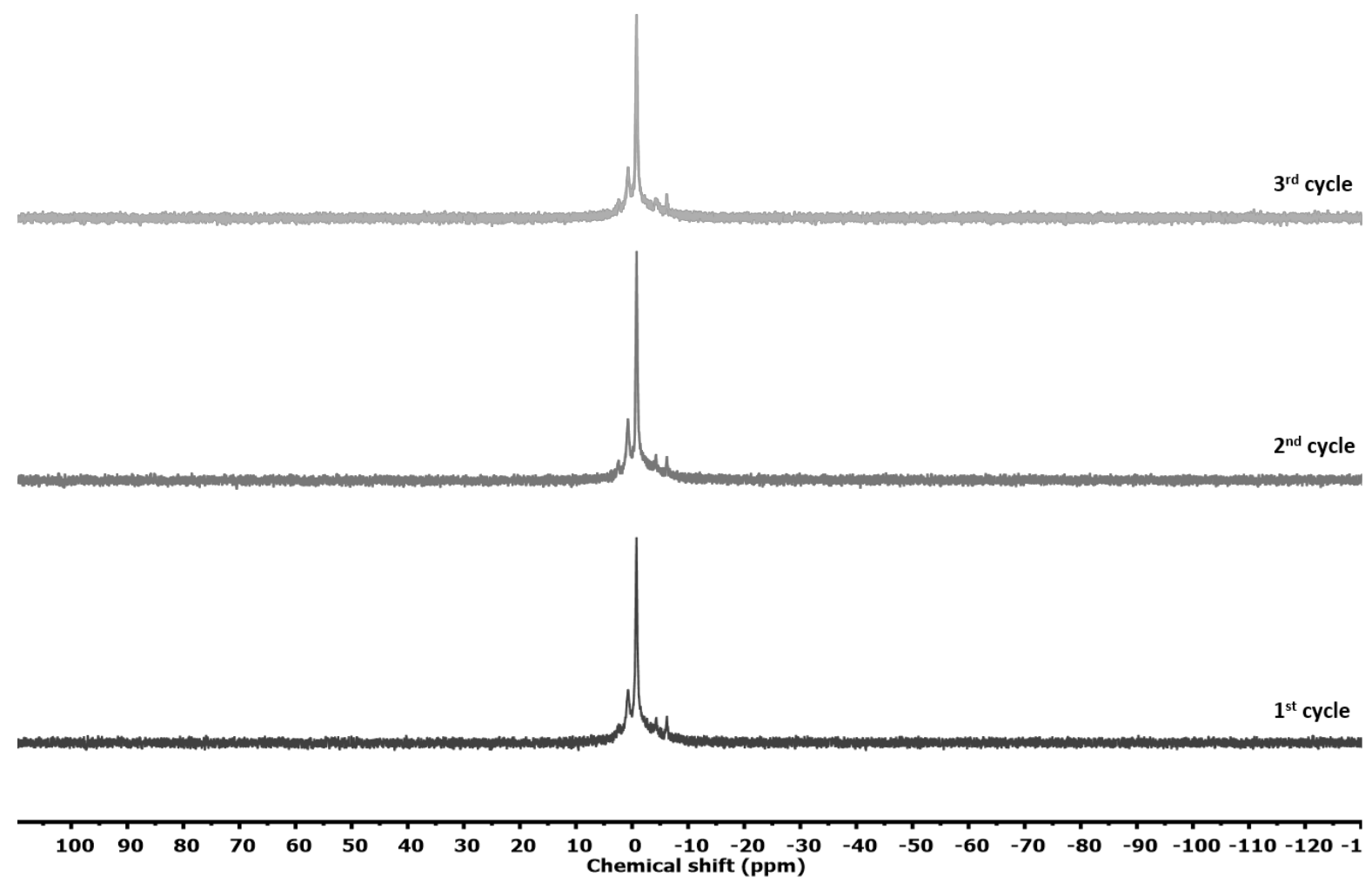

Figure S11. ${ }^{31} \mathrm{P}$ NMR spectra of pTHF-PX swollen in $\mathrm{CDCl}_{3}$ in subsequent reprocessing cycles showing no significant chemical alteration at the phosphate triester crosslink after 3 cycles of processing. 
Extent of network degradation by hydrolysis
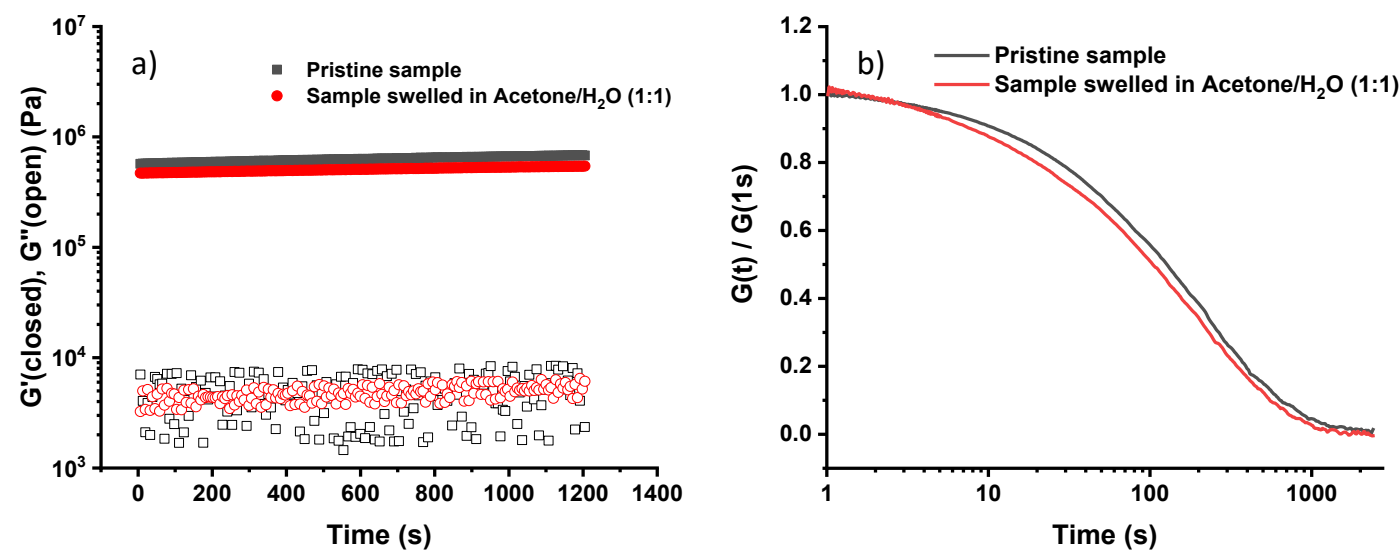

Figure S12 a) Time oscillation experiment, b) stress relaxation experiment on pristine pTHF-PX sample and freeze-dried sample after swelling in acetone-water mixture for $25 \mathrm{~d}$.

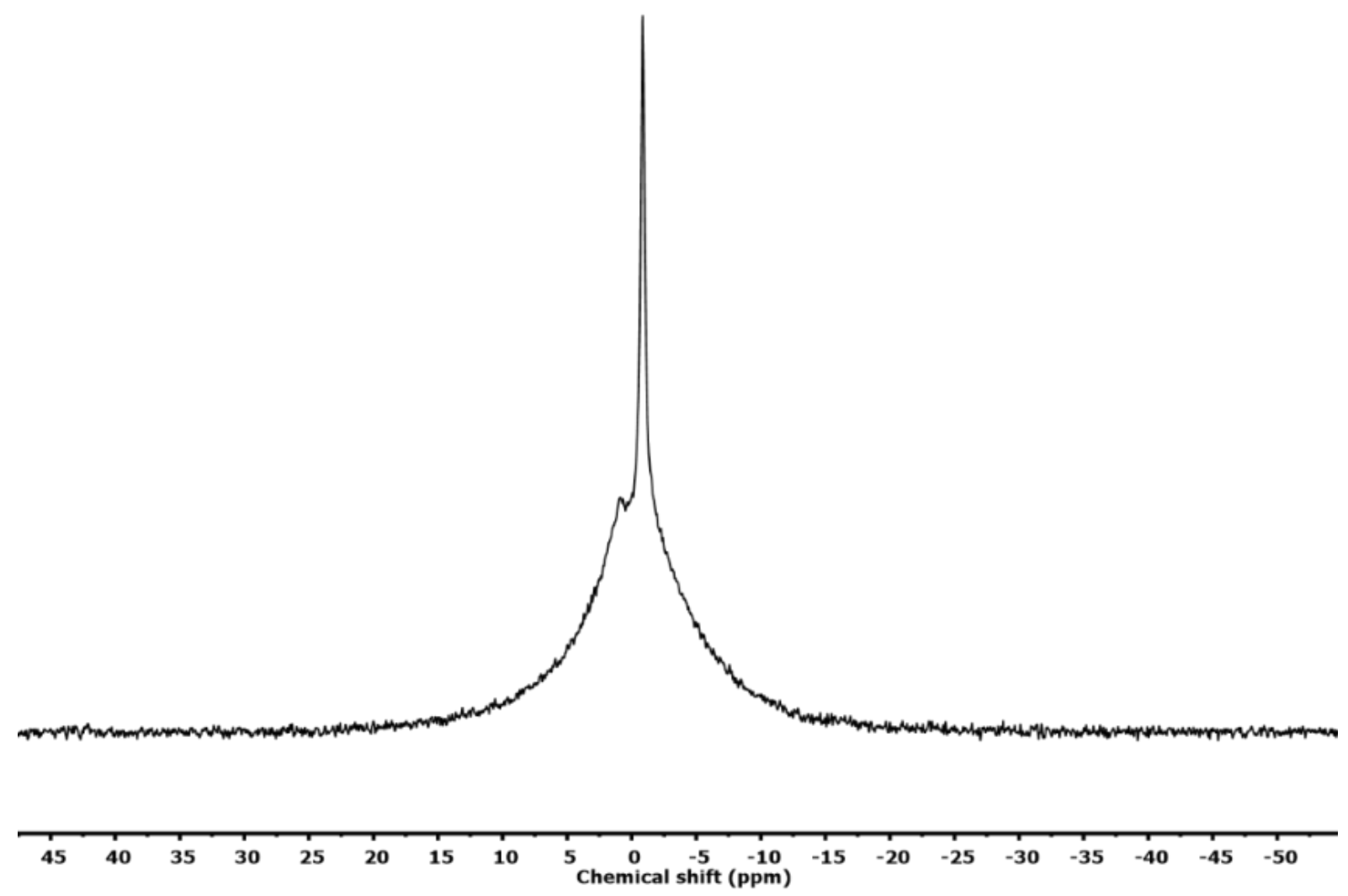

Figure S13. ${ }^{31} \mathrm{P}$ NMR of pTHF-PX-diester swollen in $\mathrm{CDCl}_{3}$ 

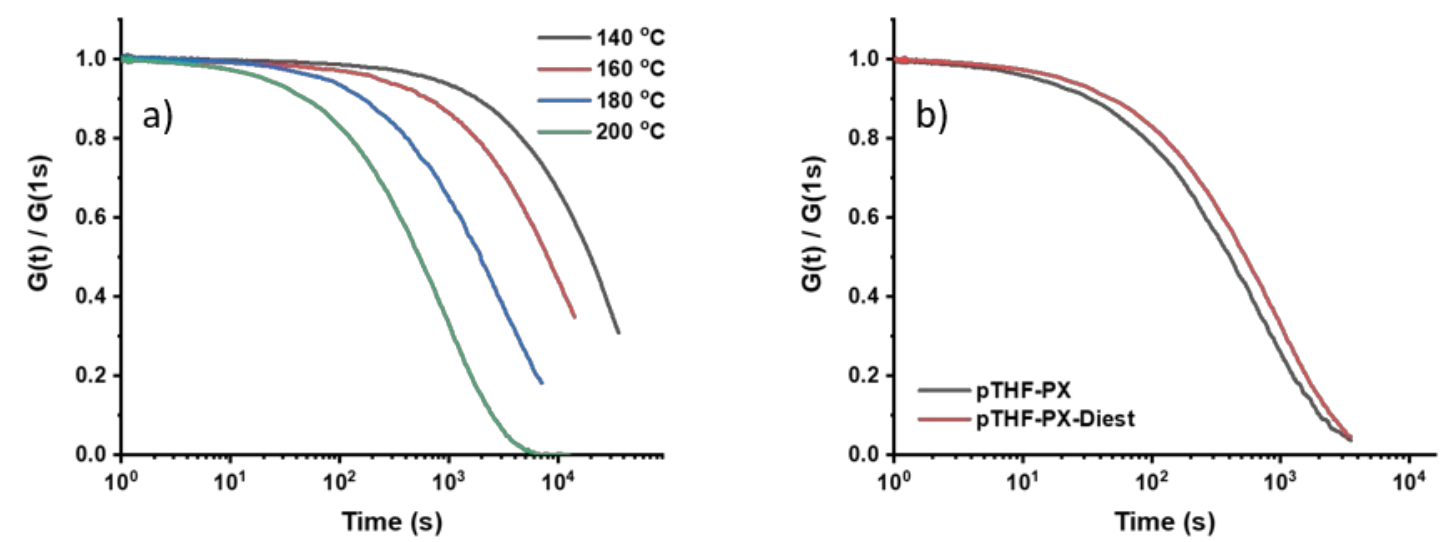

Figure S14. a) Stress relaxation experiment on PTHF-PX-diester with temperature variation. b) Comparison of stress relaxation rates of PTHF-PX and PTHF-PX-diester at $200^{\circ} \mathrm{C}$. Addition of excess sodium salt of phosphate diester monoanion does not enhance the relaxation rates. This suggests that the inbuilt sodium salt does not act as a catalyst in the exchange process that is responsible for the network rearrangement.

\section{AAS and SEM-EDS on PTHF-PX and pTHF-PX-diester}

a
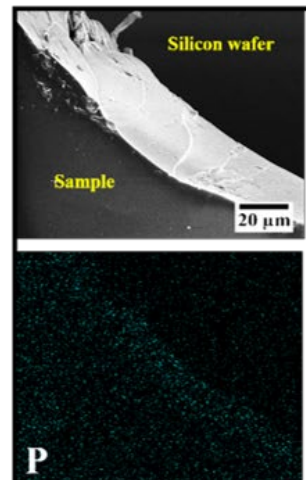

$\mathbf{P}$
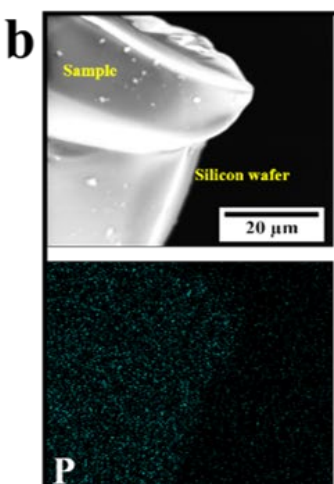
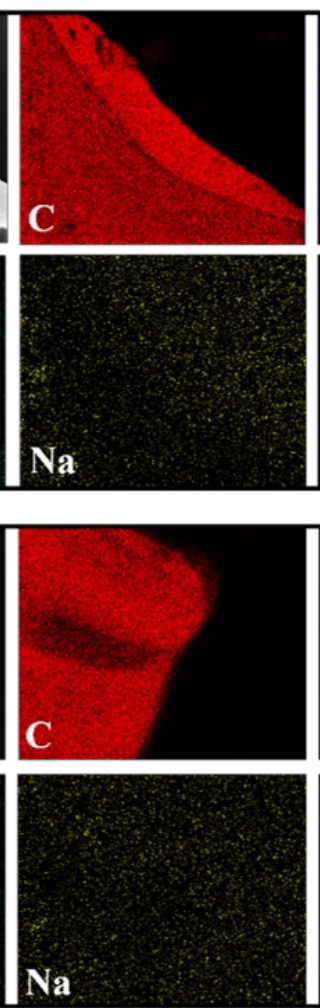
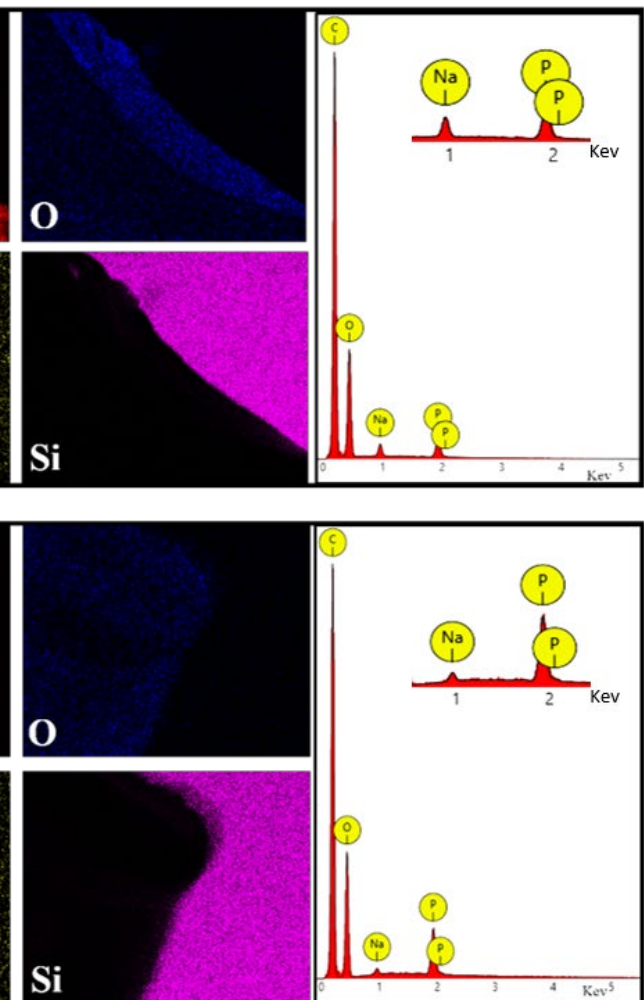

Figure S15. SEM-EDS mapping, red= carbon; blue= oxygen; green= phosphorus; yellow= sodium; purple= silicon (from silicon wafer), on a) pTHF-PX-diester, b) pTHF-PX. The poor $\mathrm{S} / \mathrm{N}$ ratio in case of sodium mappings in both samples reconfirm the low sodium content in the samples. EDS spot measurement spectra (right). EDS analysis shows that sodium content in PTHF-PX-diester is higher than that of pTHF-PX which is in agreement with the AAS results. 
Table S5. Amount of sodium in $500 \mathrm{mg}$ of sample from AAS.

\begin{tabular}{|l|l|l|}
\hline & Sodium content (wt) (mg) & Sodium content (wt\%) \\
\hline pTHF-PX & 0.26 & $0.05 \%$ \\
\hline pTHF-PX-diester & 0.94 & $0.19 \%$ \\
\hline
\end{tabular}

The $\mathrm{Na}$ to phosphate ratio was estimated semi-quantitatively to be $0.24: 1$ for PTHF-PX and 0.67:1 for pTHF-PX-diester from EDS spot measurements, while the overall distribution within the sample is shown in the SEM-EDS mapping (Figure S15).

\section{Reference}

(1) Treloar, L.R.G., 1975. The physics of rubber elasticity. Oxford University Press, USA.

(2) Mark, J.E. and Erman, B., 2007. Rubberlike elasticity: a molecular primer. Cambridge University Press. 